\title{
INSTRUMENTOS ECONÔMICOS DE PROTEÇÃO DO MEIO AMBIENTE: REFLEXÕES SOBRE A TRIBUTAÇÃO E OS PAGAMENTOS POR SERVIÇOS AMBIENTAIS*
}

\section{ECONOMIC INTRUMENTS OF ENVIRONMENTAL PROTECTION: REFLEXIONS ABOUT THE TAXATION ENVIRONMENTAL AND THE PAYMENTS FOR ENVIRONMENTAL SERVICES}

\author{
Carolina Vieira Ribeiro de Assis Bastos
}

\begin{abstract}
Resumo: Este artigo tem por objetivo refletir sobre os instrumentos econômicos para a proteção do meio ambiente. Primeiramente, apresenta dois instrumentos, a tributação ambiental e os pagamentos por serviços ambientais. Em seguida, faz algumas críticas aos mecanismos econômicos de proteção do meio ambiente e analisa o fundamento dos mesmos.
\end{abstract}

Palavras-chave: Tributação. Serviços ambientais. Proteção do meio ambiente.

\begin{abstract}
This paper aims to reflect about the economic instrument to the environmental protection. At the first, presents two instruments, environmental taxation and the payments for environmental services. After that, does some critiques to the economic mechanisms of environmental protection and analyzes the their basis.
\end{abstract}

Keywords: Taxation. Environmental services. Environmental protection.

\section{INTRODUÇÃO}

A tensão entre desenvolvimento e meio ambiente traduziu-se na incapacidade do sistema econômico para proteger o meio ambiente, exigindo a intervenção do Estado. Neste sentido, passou-se a buscar a idéia de um desenvolvimento equilibrado, sustentável, que integrasse a proteção do meio ambiente como fator necessário à qualidade de vida.

Assim, o direito ao meio ambiente foi reconhecido como direito subjetivo pela maior parte dos ordenamentos constitucionais (art. 225, CF) e sua defesa foi colocada como princípio diretivo da política econômica (art. 170 VI CF).

" Artigo desenvolvido na disciplina Direito Tributário, no primeiro semestre de 2007, sob supervisão da Prof ${ }^{-}$Dra. Marlene Kempfer Bassoli.

** Mestranda em Direito Negocial pela Universidade Estadual de Londrina-PR. 
Por isso, a proteção do meio ambiente facultou ao poder público, a intervenção na utilização dos recursos naturais e na condução da atividade econômica. Há diversas formas de intervenção, mas recentemente têm recebido especial atenção os instrumentos econômicos de proteção do meio ambiente.

O presente trabalho tem por objetivo abordar dois instrumentos que podem ser empregados na defesa do meio ambiente: a tributação e os pagamentos por serviços ambientais. Em seguida, pretende levantar algumas críticas a tais instrumentos, bem como analisar seus fundamentos.

\section{OS INTRUMENTOS ECONÔMICOS DE PROTEÇÃO DO MEIO AMBIENTE}

No seio da economia de mercado e recebidos com grande polêmica no campo da política ambiental, os instrumentos econômicos vieram a complementar as estratégias de defesa do meio ambiente. Através da pressão indireta exercida sobre as atividades contaminantes, influenciam principalmente o custo de bens e serviços, incitando condutas menos contaminantes (HERNÁNDEZ, 1998).

A utilização dos mecanismos econômicos no campo ambiental é relativamente recente. Isto porque a regulamentação administrativa baseada em medidas sancionatórias era mais facilmente compreendida pela população do que complexos dispositivos de mercado. Além disso, por um tempo, a indústria mostrou-se reticente a tais mecanismos argumentando que originavam custos suplementares que encareciam os produtos e inviabilizavam a competitividade nos mercados internacionais (HERNÁNDEZ, 1998).

No entanto, os métodos empregados pelos organismos administrativos, baseados principalmente em medidas repressivas, resultaram insatisfatórios. Neste contexto, a partir da última década as políticas ambientais, tendo em vista a eficácia na proteção do meio ambiente, passaram a enfatizar o uso de instrumentos menos repressores e mais incentivadores.

Segundo Altamirano (2003), quatro elementos caracterizam os instrumentos econômicos: a existência de um estímulo financeiro; a faculdade do agente contaminador de reagir livremente diante deles; a intervenção estatal e a finalidade protetora do meio ambiente. Apesar da inegável contribuição de tais instrumentos para a eficácia das políticas ambientais, a principal crítica que se levanta é que o enfoque meramente economicista pode conceder ao sujeito contaminante um verdadeiro direito a contaminar.

Há diferentes tipos de instrumentos econômicos utilizados para a proteção do meio ambiente. Dentre eles, analisar-se-á a seguir: os instrumentos fiscais, que tomados pela administração visam reduzir a degradação através da redistribuição dos custos empregados ou de benefícios econômicos ou fiscais e, 
Instrumentos econômicos de proteção do meio ambiente

a idéia de mercados de serviços ambientais, que através da criação de um mercado permite aos contaminadores comprar, em quantidade e tempo limitados, direitos de contaminação.

\subsection{A tributação ambiental}

A utilização de instrumentos tributários para a proteção do meio ambiente não se trata de função primordial do tributo, que é de servir como instrumento jurídico financeiro ao Estado para arrecadar recursos capazes de garantir as necessidades públicas.

A idéia de utilizar o tributo para corrigir disfunções sócio-econômicas, surgiu em 1920, quando o economista britânico Pigou, em A economia de Bem-Estar ${ }^{1}$, sugeriu que as falhas do mercado fossem corrigidas através da internalização de uma determinada externalidade social a cargo dos sujeitos responsáveis pela mesma. No caso ambiental, essa internalização significou impor gravames que incorporassem ao preço do produto o custo da contaminação (HERNÁNDEZ, 1998).

Pigou diferenciou os custos privados dos custos sociais. Os primeiros são os que as empresas contabilizam, os segundos são os que realmente custam à comunidade e, a diferença entre eles são as externalidades. Essa distinção implicava afirmar que as empresas experimentam privadamente um custo mais baixo que o social, questionando o modelo de equilíbrio ${ }^{2}$, então defendido, cuja conclusão essencial era que o sistema de mercado atuando em competição perfeita fazia a melhor atribuição possível dos recursos de produção e dos bens de consumo (ALTAMIRANO, 2003).

Pigou chamou os efeitos sociais danosos da produção privada de deseconomias externas e os efeitos de aumento de bem-estar social da produção privada de economias externas. Então, havendo uma falha de mercado o Estado deveria intervir, corrigindo-a. Em se tratando de uma deseconomia externa, deveria introduzir um sistema de imposto, já no caso de uma economia externa deveria atuar por meio de subsídios ou incentivos fiscais (DERANI, 2001).

${ }^{1}$ A análise de Pigou surgiu de um precedente jurisprudencial britânico, cujo objeto era uma demanda promovida por agricultores dos campos pelos quais atravessavam locomotoras e provocavam faíscas que incendiavam tais campos; por conseqüência os agricultores deveriam pagar maiores quantias de seguro (ALTAMIRANO, 2003, p. 41).

${ }^{2}$ A ideologia econômica da época baseava-se na idéia da "mão invisível", segundo a qual as disfunções poderiam ser corrigidas dentro da própria estrutura de mercado, mediante o livre jogo das forças econômicas. Diante da ineficácia dessa idéia passou-se a defender o papel do Estado como regulador dos aspectos negativos (HERNANDÉZ, 1998, p. 77). 
A degradação do meio ambiente é um exemplo típico de externalidade negativa e o princípio do poluidor-pagador fundamenta-se no objetivo de internalizar os custos externos de uma degradação. Através da aplicação deste princípio impõese ao sujeito econômico, que tenha causado um problema ambiental, que arque com os custos da diminuição ou afastamento do dano.

Assim, a responsabilidade individual ou a internalização dos custos sociais constitui o ponto de partida da discussão tributário-ambiental. A introdução do elemento ecológico na estrutura tributária estabelece uma série de instrumentos cujo denominador comum é gravar as atividades que direta ou indiretamente prejudiquem o meio ambiente.

Neste sentido, no que tange à natureza, Hernández (1998) distingue os tributos ambientais em: os que perseguem uma redistribuição do custo da proteção ou reparação do meio ambiente e aqueles que buscam incentivar condutas menos danosas para o meio ambiente. No primeiro caso, dos tributos ecológicos redistributivos, o fato imponível consiste na prestação dos serviços públicos correspondentes (Ex: reciclagem), pelos quais se pagará, geralmente, taxas, preços públicos ou contribuições especiais ${ }^{3}$. Quanto aos tributos com função incentivadora, incidem indiretamente no agente contaminador de maneira que este busque por sua própria conveniência econômica vias alternativas menos contaminantes; nestes casos, via de regra, são utilizados os impostos (HERNÁNDEZ, 1998).

Os impostos ambientais possuem uma função sancionatória, quem contamina repara o dano gerado; ou modeladora de conduta, a qual estimula a não contaminação. Já as taxas, aplicadas no campo ambiental, podem ser analisadas sob dois aspectos: por um lado são um meio de responsabilizar o contaminador financeiramente e por outro, fixam um preço pela sua atividade impondo deste modo um preço econômico ao responsável pelo custo ecológico. Por fim, os incentivos e subsídios, ocorrem quando por razões motivadas em princípios jurídicos, no caso a proteção do meio ambiente, ainda que produzido o fato imponível do imposto, o ordenamento jurídico concede uma dispensa total ou parcial da obrigação tributária (ALTAMIRANO, 2003).

Cabe ressaltar que, há um intenso debate entre os estudiosos do assunto sobre qual seria a figura tributária mais adequada para proteger o meio ambiente. Argumenta-se que, no plano da utilização dos serviços públicos, que vinculem a administração pública com fins ambientais, as taxas ${ }^{4}$ e contribuições especiais

${ }^{3}$ Os impostos também podem levar a cabo tal função, apesar de não ser a regra, assim como as taxas podem assumir uma função incentivadora (HERNÁNDEZ, 1998). 
Instrumentos econômicos de proteção do meio ambiente

são os tributos indicados, pois refletem a opção legítima de financiamento de tais serviços. No entanto, a utilização das taxas como instrumento de internalização encontra óbices quando: há dificuldade de se identificar o sujeito responsável pela contaminação (não cumpre o caráter específico); não há como quantificar o dano causado (não cumpre o princípio da contraprestação) e, se é necessário produzir efeitos incentivadores (HERNÁNDEZ, 1998).

De outro modo, defende-se que os impostos ${ }^{5}$ se dirigem a alcançar os objetivos da política ambiental, pois como não gravam os contribuintes que ocasionam danos ambientais com os custos dos que são responsáveis, podem ser a figura central de um sistema tributário ambiental. As taxas e contribuições especiais deverão ser aplicadas somente nas atividades que assim requeiram, ou seja, são aptas a financiar os gastos causados pela contaminação, mas não para internalizar os custos sociais ou incentivar condutas (HERNÁNDEZ, 1998).

Dentre as vantagens da tributação ambiental destaca-se: a flexibilidade, que sendo característica de todo instrumento econômico, permite que não imponha nem proíba ações concretas, mas relega ao particular a eleição da via mais conveniente às suas possibilidades; a disposição para incentivar a investigação e implementação de novas tecnologias favoráveis ao meio ambiente; e, o fato de que um sistema baseado em tributos pode aproveitar na sua gestão as instituições, estrutura e pessoal das Administrações Fiscais, evitando assim gastos desnecessários (HERNÁNDEZ, 1998).

As desvantagens ou inconvenientes de se utilizar tributos como instrumento de proteção do meio ambiente, surgem da comparação com os mecanismos administrativos. Levanta-se: a dificuldade de conhecer a resposta dos agentes contaminantes e o grau em que conseguirão os objetivos propostos; a complexidade de fixar o correto tipo de tributo que reflita efetivamente o custo social que se pretenda internalizar; e, o fato de que a efetividade desses instrumentos somente é viável em longo prazo, por isso, são ineficazes em situações de emergência (HERNÁNDEZ, 1998).

${ }^{4}$ Taxas são prestações pecuniárias exigidas coativamente pela autoridade pública em caráter de contraprestação por serviço público divisível que dita autoridade presta ao sujeito ou está em condições de prestá-la. Diante desta definição alguns autores consideram limitada a relevância das taxas como instrumento econômico para a proteção ambiental (ALTAMIRANO, 2003).

${ }^{5}$ Os impostos são: "as prestações pecuniárias, que se impõem pelo ordenamento jurídico, em favor da Administração Pública, sem conexão com uma vantagem oferecida por ela” (NAWIASKY, 1982 apud CARRAZA, 2000, p. 365). 
Recentemente, passou-se a questionar ainda se os tributos são mesmo mecanismos eficazes para evitar a degradação ambiental. Outros recursos naturais, como o ar e água limpos, a proteção da camada de ozônio, estabilidade climática, biodiversidade, nem sempre conseguem ser atingidos por tais mecanismos, são os casos em que os efeitos das externalidades são gerados por um número elevado e indeterminado de sujeitos, bem como atingem um número mais indeterminado ainda, potencialmente toda a humanidade.

\subsection{Os pagamentos por serviços ambientais}

Na última década, o debate sobre os serviços ambientais tornou-se popular. Os Pagamentos por Serviços Ambientais (Payments for Environmental Services) também optam por uma perspectiva econômica com relação ao direito e ao meio ambiente.

Trata-se de um novo instrumento de promoção da sustentabilidade ambiental, que coloca o meio ambiente como uma nova classe de mercadoria disponível em transações de mercados, pelo qual todos nós devemos pagar. O termo "serviços ambientais" foi originalmente cunhado por economistas e agora aparece com freqüência em documentos produzidos pelos governos, pelo Banco Mundial e outras organizações internacionais, universidades, associações comerciais, organizações não governamentais e organizações sociais (GRAIN, 2005).

Segundo Born e Talocchi (2002), subjaz à idéia de serviço ambiental a necessidade de se manter a capacidade da natureza de reproduzir as condições ambientais que sustentam a vida no planeta. Escolhe-se uma visão bastante utilitarista da natureza, na qual esta é vista como uma espécie de "usina" que produz "recursos", ou melhor, "serviços", necessários ao bem-estar dos seres vivos, principalmente do homem.

A tendência ao uso de mecanismos de caráter econômico para a gestão ambiental apóia-se em princípios como o poluidor-pagador, usuário-pagador e protetor-recebedor. Este último é o que fundamenta o pagamento pelos serviços ambientais. Soma-se ainda o argumento de que o dinheiro resolve mais do que leis e decretos, em outras palavras, que mercado e economia sobrepõem-se à política, à justiça e aos direitos (BORN; TALOCCHI, 2002).

A terminologia e definição legal dos pagamentos por serviços ambientais ainda encontra-se em processo de formação, mas já entraram em nossa consciência coletiva, tanto que há alguns anos existem verdadeiros mercados desses serviços. Neste sentido, cabe a reflexão sobre o assunto, pois a escolha pela propagação de tais serviços não pode ser aceita como óbvia e inquestionável.

Os pagamentos por serviços ambientais enfatizam uma forma de intervenção direta em favor da proteção do meio ambiente. Baseiam-se em modelos de compra 
Instrumentos econômicos de proteção do meio ambiente

e venda, nos quais os vendedores entregam os resultados da conservação em troca dos pagamentos negociados. Recentes debates discutem os pagamentos por serviços ambientais através da comparação entre os mecanismos diretos e indiretos.

Segundo Ferraro e Kiss (2002), institucionalmente, ambos os mecanismos exigem instituições que possam monitorar os ecossistemas, resolver conflitos e coordenar comportamentos individuais, alocar e executar direitos e responsabilidades. No entanto, os pagamentos por serviços ambientais requerem uma menor complexidade institucional e custos mais baixos para implementação. Além disso, pesquisas apontam no sentido de que residentes de áreas rurais conservadas por pagamentos podem lucrar duas vezes mais do que com intervenções indiretas.

Argumenta-se ainda que os pagamentos por serviços ambientais possam colocar muitas regiões cujas práticas de conservação estão à margem da economia para gerar retornos substanciais. Assim, os pagamentos por serviços ambientais não só beneficiam fazendeiros pobres, como concedem maior liberdade para os mesmos decidirem como atingir seus objetivos e aspirações, do que os subsídios que geralmente predeterminam suas atividades (FERRARO; KISS, 2002).

Portanto, o princípio básico é o de que o modo mais barato de conseguir algo que se queira, por exemplo, proteção de uma floresta tropical, é pagar por ele. A negociação desses serviços tem por principais esferas de ação: o seqüestro de carbono, a captura e armazenamento de água, conservação da paisagem e da biodiversidade.

O processo de estabelecimento de um esquema de venda de um serviço ambiental começa com um projeto de conservação, de ecoturismo ou um projeto relacionado à água. A maioria dos projetos tem apoio governamental, no entanto, é comum verificar-se a iniciativa do setor privado e esforços de organizações não governamentais. Em tais projetos oferece-se às comunidades locais um pagamento anual pela conservação de áreas naturais ou florestas e, em troca as comunidades devem implementar um plano de manejo definido por governos ou agências privadas (GRAIN, 2005).

Cada plano de manejo deve ter um impacto zero sobre o meio ambiente, o que significa que nada deve ser removido ou interferido. Além disso, freqüentemente, principalmente nos projetos de ecoturismo e água, as comunidades envolvidas devem investir em infra-estrutura e marketing, o que acaba resultando em empréstimos e débitos (GRAIN, 2005).

Neste sentido, há três impactos imediatos nas comunidades envolvidas em cada projeto de conservação: perda do controle sobre uma mínima parte de seu território; dívidas que podem levar à perda da terra e, medidas punitivas financeiras 
e legais em caso de não cumprimento do plano de manejo. Assim, pode-se prever o potencial de expropriação, marginalização, repressão, exploração e divisão interna de comunidades (GRAIN, 2005).

De outro modo, pode-se estabelecer um serviço ambiental pela privatização de um parque nacional, o qual é dado às empresas privadas ou ainda, mais comum, se cria uma fundação ou organização não governamental de conservação. A essas empresas ou ONGs são dadas concessões para administrar áreas naturais por longos períodos de tempo e em troca da promessa para conservar confere-se liberdade para lucrar com os recursos naturais (GRAIN, 2005).

Uma das mais sérias conseqüências deste novo acesso ao gerenciamento de recursos naturais é a possibilidade dos governos assumirem a autoridade para conceder ou reconhecer o direito de comunidades sobre territórios que historicamente sempre estiveram sob seu controle. Os governos são potencializados a tirar tais direitos se certas condições não forem preenchidas ou ainda, reduzir à propriedade à terça parte, incluindo empresas e ONGs (GRAIN, 2005).

Os governos também assumem o direito a privatizar ${ }^{6}$ grandes pedaços de terra, muitos dos quais foram tomados em primeiro lugar de povos indígenas e podem ser parte de uma herança pública ou nacional. Segundo estudiosos do assunto, a privatização da natureza, incluindo povos indígenas e pequenos fazendeiros, tem aumentado para níveis nunca antes vistos e os serviços ambientais estão sendo oferecidos como um mecanismo de expropriação e concentração da propriedade de terras (GRAIN, 2005).

Com base nos direitos de propriedade de Coase, procura-se estimar um valor para o uso dos recursos naturais conforme o mercado. Segundo Derani (2001), determinando-se um preço à natureza, privatiza-a, imputando ao utilizador deste recurso uma contraprestação monetária. Adverte ainda que, uma relação dependente de uma situação econômica não garante a proteção efetiva do meio

${ }^{6}$ Os direitos de propriedade intelectual moveram a agenda internacional da OMC, mas eles não permitiram a privatização de tudo. Para reivindicar algo como propriedade é necessário no mínimo descrever e reconhecer um animal, um organismo, uma planta ou um gene, então como fazer com os elementos vivos que ainda não são conhecidos ou cujas funções ainda não são explicitamente conhecidas? Por exemplo, sobre óleos, minerais, ar, água, oxigênio, chuva ou a capacidade de organismos mortos para decompor e purificar o ar ou regular o clima? Segundo alguns analistas, tudo isto não poderia ser reivindicado como propriedade intelectual e a solução encontrada constitui-se em um lento ataque, não somente contra o Estado, mas contra o que é público e coletivo, por meio dos serviços ambientais (GRAIN, 2005, p. 6). 
Instrumentos econômicos de proteção do meio ambiente

ambiente, pois sujeita-se a outros critérios como existência de mercado, situação concorrencial, flutuações entre crises e aquecimento de consumo etc. Além disso, quanto maior o preço da mercadoria, menor a quantidade de sujeitos que têm acesso a ela e, a qualidade de vida torna-se um bem de mercado acessível a quem detém riqueza e disponibilidade para pagá-la.

No entanto, os instrumentos econômicos alcançam alguma efetividade na proteção do meio ambiente, e sendo esta uma tarefa hercúlea, não podem ser ignorados. Uma das formas de minimizar os riscos deste instrumento meramente econômico tem sido articular a dimensão ecológica com a social.

Neste sentido, defendem Born e Talocchi (2002) que, os mecanismos econômicos ambientais são úteis, mas que devem observar e promover a justiça social, que se caracteriza pela equidade, pela inclusão social e que a integridade ambiental deve se pautar no princípio da responsabilidade comum diferenciada. Segundo este princípio, os que mais poluem atualmente ou mais degradaram o planeta ao longo da história têm uma dívida ecológica com os países e povos de menor desenvolvimento material e econômico, pois como causaram menores impactos devem arcar menos com as ações necessárias ao desenvolvimento sustentável.

Argumenta-se ainda que, o direito a receber um pagamento por tal espécie de serviço deve associar-se a algo que ultrapasse a obrigação de todos de proteger o meio ambiente. Pelo contrário, se o sistema premiar aqueles que fazem menos que o mínimo, para que corrija em certo lapso temporal o que deveriam ter feito, institucionalizaria um tratamento igualitário entre poluidores e não poluidores.

Born e Talocchi (2002) advertem a necessidade de se analisar profundamente as responsabilidades e obrigações em jogo na adoção desses serviços. Defendem a imperativa aplicação e operacionalização precisa do conceito de compensação por serviços ambientais, pois somente o estabelecimento de regras claras pode evitar efeitos perversos. Neste sentido, é premente uma redefinição do que seriam bens privados, bens comuns públicos e bens coletivos. A titularidade dos recursos naturais é complexa e as tradicionais definições jurídicas não são suficientes, soma-se ainda o fato de que, o enfrentamento desse problema é uma questão política, de acesso à direitos e equidade social, não se restringe à uma questão de técnica jurídica.

Para que a efetividade dos mercados de serviços ambientais se some à equidade, tem-se defendido que eles precisam: alcançar uma forma adequada de atribuir valor aos ecossistemas; distribuir adequadamente os direitos entre os proprietários; fazer valer as regulamentações de mercado; nivelar produtores e consumidores de tais mercados, de maneira que possam participar equitativamente. No entanto, esses fatores não têm sido devidamente observados quando da implementação dos mercados. 


\section{ALGUMAS CONSIDERAÇÕES SOBRE OS INSTRUMENTOS ECONÔMICOS DE PROTEÇÃO DO MEIO AMBIENTE}

Subjaz a esses instrumentos uma determinada concepção do direito, sobre a qual cabe a reflexão. A descrição da norma por meio de conceitos não muito claros pode levar a conseqüências indesejadas. Tanto na proposta de tributação ambiental quanto na criação de mercados de serviços ambientais está presente uma concepção marcadamente econômica do Direito.

No entanto, cabe ressaltar que em que pese essa concepção econômica, as propostas se diferenciam, pois, enquanto a tributação procura racionalizar o uso dos recursos naturais, trazendo o Estado para neutralizar seus efeitos negativos; a inserção do bem ou serviço meio ambiente no mercado pode até otimizar sua utilização econômica, mas o enquadra dentro de uma política empresarial e não de uma política pública.

\subsection{A concepção de direito adotada}

$\mathrm{Na}$ década de 70 surge uma tendência teórica que impressionou os estudiosos do direito ao buscar a audaciosa combinação entre direito e economia, a Laws and Economics ou Análise Econômica do Direito. Esta teve início pelos trabalhos de, Ronald $\mathrm{H}$. Coase (The Problem of Coust Social-1960), o qual analisa o problema do custo social ou efeitos externos produzidos pelas atividades econômicas, criticando a Economia de Bem Estar, e de Guido Calabresi (Some Thougts on Risk Distribuition and the Law of Tourts-1961), que examina a distribuição do risco como critério de imputação da responsabilidade que informa o direito de danos. Porém, recebeu novo e significativo impulso com a publicação de Richard Posner, Economic Analisys of Law (1973), o qual finalmente consolidou o movimento teórico (ALVAREZ, 2006).

Isto porque, a obra de Posner foi um estudo sistemático da maioria dos setores do sistema jurídico americano, desde a perspectiva da análise econômica e continha as principais teses da tendência predominante na Escola de Chicago e da teoria do direito a partir do paradigma do mercado e da eficiência econômica (ALVAREZ, 2006).

Para a Análise Econômica do Direito, os indivíduos são racionais e se comportam tentando maximizar seus interesses em todos os âmbitos e facetas de sua vida, por isso, o Direito é um conjunto de incentivos que premia as condutas eficientes e penaliza as ineficientes. Em decorrência, o valor econômico eficiência ou o princípio da maximização da riqueza podem ser usados pelos juízes como modelo para determinar quando uma decisão pode ser considerada justa (ALVAREZ, 2006). 
Instrumentos econômicos de proteção do meio ambiente

Conforme Alvarez (2006), a aplicação da teoria econômica à realidade jurídica implica adotar a perspectiva econômica como referencial analítico da regulação e do sistema jurídico, o que por conseqüência estabelece um novo tipo de relação, na qual a interpretação e avaliação de uma norma realizam-se desde os pressupostos da teoria econômica. Então, a racionalidade subjacente à norma é uma racionalidade econômica e coloca no centro dos estudos jurídicos os problemas relativos: à eficiência do direito, aos custos dos instrumentos jurídicos na persecução de seus fins e as conseqüências econômicas das Intervenções Jurídicas.

Além disso, a reconstrução do discurso jurídico se dá por uma linguagem tecnocrática, pois os destinatários desse discurso não são indivíduos ou grupos, mas operadores que partem de uma visão funcional e operacional do direito. Assim, o direito passa a ser compreendido como meio para atingir fins ou objetivos sociais, por isso, conforme a maioria dos teóricos dessa corrente os valores e objetivos das normas jurídicas devem derivar dos desejos e interesses reais da sociedade num determinado momento (ALVAREZ, 2006).

Em defesa da Análise Econômica do Direito, argumenta-se que a teoria procura explicar o pensamento jurídico partindo do comportamento dos indivíduos perante as regras e os efeitos destas na obtenção de resultados eficientes. Segundo Pacheco, isto é possível porque de fato o direito influi no comportamento dos indivíduos e tal influência é de natureza econômica (ALVAREZ, 2006).

Sob a ótica econômica, destaca Pacheco, depois de fixada a prioridade da ação racional econômica e o fim da ação do ponto de vista da eficiência econômica, o Direito converte-se num conjunto de incentivos e guias que encaminham a conduta dos indivíduos para a consecução do fim específico que deve perseguir, no caso, a eficiência econômica (ALVAREZ, 2006).

A Análise Econômica do Direito começou a produzir explicações nos mais variados campos jurídicos e isto pode ser claramente identificado no campo do direito ambiental. Em ambos os casos referidos neste artigo, na tributação ambiental e nos pagamentos por serviços ambientais percebe-se a concepção de direito aqui cunhada, ou seja, o Direito como um conjunto de incentivos que premia as condutas eficientes e penaliza as ineficientes.

\subsection{Riscos e contribuições}

Dworkin (2003) afirma que, a Análise Econômica do Direito satisfez algumas exigências de adequação às nossas práticas jurídicas, pois de fato alguns padrões conhecidos podem ser identificados com a aplicação do princípio econômico por isso, não pode ser rejeitada. No entanto, nem sempre as decisões jurídicas podem ser objeto de uma negociação hipotética ou submetida a outros parâmetros 
econômicos. Neste sentido, afirma que se restringíssemos nossas escolhas, nossas responsabilidades, apenas às situações de mercado, a autonomia pessoal praticamente desapareceria, pois numa sociedade cujos membros aceitam a simulação de mercado como um dever, tal dever nunca estaria inativo.

Uma das principais críticas aos mecanismos econômicos é que somente são possíveis em âmbitos espaciais e temporais bem determinados, por isso, sua utilização deve ser apenas complemento de medidas administrativas formando os chamados sistemas mistos, nos quais o predomínio de um ou outro mecanismo dependerá do tipo de problema a ser enfrentado (HERNÁNDEZ, 1998).

Além disso, ressalta-se que, ainda que busquem objetivos políticos, econômicos e ambientais, esses mecanismos se apóiam em um individualismo metodológico integrado por uma perspectiva econômica isolada. A economia ambiental apenas mostra como tratar a natureza de maneira que se retire dela um máximo de utilidade privada e ao mesmo tempo integre o meio ambiente na economia de mercado, por isso, acaba desconsiderando a complexidade da questão ecológica (DERANI, 2001).

Segundo Derani, tais modelos precisam encontrar a devida contextualização, sobretudo porque a valorização da natureza é artificiosa, por isso, necessita do correto amparo jurídico e político para alcançar o fim almejado. Além disso, o Estado depara-se com peculiaridades na problemática ambiental que nem sempre pode resolver com eficiência, sua ação é limitada pelos seguintes pontos: a globalidade dos problemas ecológicos e seu efeito na base de reprodução social; o caráter social e cultural da crise ecológica; o caráter inédito e irreversível dos experimentos ecológicos e, o caráter histórico mundial que chegou tal crise (DERANI, 2001).

Optar por uma perspectiva meramente economicista com relação à problemática ecológica implica relegar ao direito ambiental um papel puramente instrumental. Não basta que a política ambiental seja economicamente justa e adequada, ela precisa se apoiar em aspectos morais e éticos, ponderá-los e levar em consideração o interesse das pessoas afetadas. Por isso, a atuação do Estado na proteção dos recursos naturais não pode ser isolada, dissociada de questões culturais, econômicas e de capacidade técnica, nem se restringir ao problema da internalização dos custos sociais, sem envolvimento dos diversos setores da sociedade.

Neste sentido, entende-se que tais instrumentos são úteis na proteção do meio ambiente e não podem ser desconsiderados. No entanto, é necessário observar atentamente sua implementação, garantir que cumpram os princípios elencados na Constituição. No caso da tributação, seu caráter extrafiscal deve ser absolutamente combinado com os princípios da legalidade, da tipicidade e da 
Instrumentos econômicos de proteção do meio ambiente

capacidade contributiva. Já os pagamentos por serviços ambientais não podem ser simplesmente aceitos pelo nosso ordenamento, já que estão sendo amplamente empregados em outros países, antes terão de ser normativamente construídos de tal maneira que se garanta o respeito a princípios como a igualdade, erradicação da pobreza e função social da propriedade.

Portanto, o Estado e a coletividade devem assumir o papel de ativos fiscalizadores, essa seria uma postura de vanguarda na proteção do meio ambiente, ou seja, que empregasse os instrumentos econômicos de proteção do meio ambiente, os quais de fato já existem e não se pode retroceder, mas que também articulasse todos os setores da sociedade, pois a complexidade do problema ecológico não pode enfrentada de forma isolada e fragmentada.

\section{CONCLUSÃO}

A proteção do meio ambiente é uma tarefa titânica, por isso, deve levar em consideração todos os instrumentos que contribuam para sua realização. Os instrumentos econômicos têm tido especial contribuição, pois são instrumentos que procuram articular meio ambiente e desenvolvimento econômico. Este trabalho limitou-se a analisar dois deles, a tributação e o pagamento por serviços ambientais.

No que tange à utilização da tributação para correção dos problemas ambientais, esta se justifica em seu caráter extrafiscal e no princípio do poluidorpagador. No entanto, deve-se buscar a categoria idônea e a viabilidade jurídica para o problema em questão, proteção do meio ambiente e/ou internalização de custos sociais, bem como respeitar os princípios constitucionais tributários.

Cabe ressaltar, que nem sempre o instrumento tributário é o apto para enfrentar um determinado problema ecológico, por isso, deve ser compatibilizado com outros instrumentos administrativos, como alguns autores defendem, é necessário um sistema misto que combine intervenções diretas e indiretas, ou instrumentos administrativos e econômicos.

No que se refere aos pagamentos por serviços ambientais, ao lado da eficiência temos de observar os riscos de que surjam efeitos perversos na sua implementação, como a possibilidade de atores fortemente articulados na sociedade, os quais detêm poder político e econômico a se apropriarem desses serviços, de tal maneira que mais uma vez o direito estaria sendo usado para benefício de somente alguns.

Além disso, o desequilíbrio de comprometimento na proteção do planeta entre países desenvolvidos e não desenvolvidos; não pode ser perpetuado pela negociação desses serviços, cita-se o exemplo dos créditos para patrocinar projetos 
Carolina Vieira Ribeiro de Assis Bastos

de Mecanismos de Desenvolvimento Limpo. Além disso, não se pode desconsiderar o risco potencial de não se reconhecer atividades preservacionistas tradicionais de populações indígenas e caboclas, tendo em vista a comparação com grandes áreas privadas gestionadas por grandes empresas.

Por isso, a implementação desses serviços deve respeitar preceitos éticos e morais, para que na negociação desses serviços ambientais, a dimensão humana não seja colocada em segundo plano.

Percebe-se ainda que estudar o conceito de direito ou o fundamento subjacente a tais instrumentos implica refletir sobre o modelo de sociedade e o correspondente papel que relegaremos ao Direito e ao sistema jurídico. Diante da faticidade da economia de mercado, é inegável que por vezes a perspectiva econômica, o caráter eficiência e o cálculo custo-benefício predominarão. Porém, o Direito não pode ser reduzido a esse aspecto instrumental, pois ele também possui um caráter deontológico e uma pretensão de responder, ainda que de maneira relativa, às demandas da sociedade por justiça.

$\mathrm{Na}$ perspectiva do direito ambiental, a defesa do meio ambiente desenvolveuse concomitantemente à idéia de participação popular, pois o direito deveria também assumir um papel pedagógico. Neste sentido, a adoção por instrumentos econômicos deve incorporar além da proteção do meio ambiente a realização da democracia. A tributação articula atividade econômica e Estado e os pagamentos por serviços ambientais tem a pretensão de envolver além de Estado e atividade econômica, a sociedade civil por meio de organizações não governamentais. Assim, resta como desafio ao Direito garantir a proteção do homem e do meio ambiente em coexistência com a racionalidade de cunho instrumental típica do sistema econômico, de forma democrática.

\section{REFERÊNCIAS}

ALTAMIRANO, Alejandro C. El derecho constitucional a um ambiente sano, derechos humanos e su vinculación com El derecho tributário. In: MARINS, James (Coord). Tributação e Meio Ambiente. Curitiba: Juruá, 2003.

ALVAREZ, Alejandro Bugallo. Análise Econômica do Direito: contribuições e desmistificações. Direito, Estado e Sociedade, Rio de Janeiro, v. 9, n. 29, p. 49-68, jul./dez. 2006.

BORN, Rubens Harry; TALOCCHI, Sergio (Coord.). Proteção do capital social e ecológico: por meio de Compensações por serviços Ambientais (CSA). São Paulo: São Lourenço da Serra; Peirópolis: Vitae Civilis, 2002. 
Instrumentos econômicos de proteção do meio ambiente

CARrAZA Roque Antonio. Curso de Direito Constitucional Tributário. São Paulo: Malheiros, 2000.

DERANI, Cristiane. Direito Ambiental Econômico. 2. ed. São Paulo: Max Limonad, 2001.

DWORKIN, Ronald. O Império do Direito. Trad: Jefferson Luiz Camargo. São Paulo: Martins Fontes, 2003.

FERRARO, Paul J.; KISS, Agnes. Direct payments to conserve biodiversity. Science, v. 298, p. 1718-9, Nov. 2002.

GENETIC RESOURCES ACTION INTERNATIONAL (GRAIN). No, air, don't sell yourself. Seedling, v. 34, Apr. 2005. Vol 34. Disponível em: <http:// mercadosambientais.com/pages/article.library.others.php?component_id= $3804 \&$ component_version_id=6315\&language_id=12>. Acesso em: 31 maio 2007.

HERNÁNDEZ, Jorge Jiménez. El tributo como instrumento de protección ambiental. Granada: Editorial Comares, 1998. 